\title{
Heat Transmission of Engine-Oil-Based Rotating Nanofluids Flow with Influence of Partial Slip Condition: A Computational Model
}

\author{
Azad Hussain 1,*, Mubashar Arshad ${ }^{1, *}$, Aysha Rehman ${ }^{1, *} \mathbb{1}$, Ali Hassan ${ }^{1}$, Sayed K. Elagan ${ }^{2}$ \\ and Nawal A. Alshehri ${ }^{2}$ (D) \\ 1 Department of Mathematics, University of Gujrat, Gujrat 50700, Pakistan; 19011709-001@uog.edu.pk \\ 2 Department of Mathematics and Statistics, College of Science, Taif University, P.O. Box 11099, \\ Taif 21944, Saudi Arabia; skhalil@tu.edu.sa (S.K.E.); nalshehri@tu.edu.sa (N.A.A.) \\ * Correspondence: azad.hussain@uog.edu.pk (A.H.); 19011709-017@uog.edu.pk (M.A.); \\ aysharehman1986@gmail.com (A.R.)
}

\section{check for} updates

Citation: Hussain, A.; Arshad, M.; Rehman, A.; Hassan, A.; Elagan, S.K.; Alshehri, N.A. Heat Transmission of Engine-Oil-Based Rotating

Nanofluids Flow with Influence of Partial Slip Condition: A Computational Model. Energies 2021, 14, 3859. https://doi.org/10.3390/ en14133859

Academic Editor: Efstathios

E. Michaelides

Received: 30 May 2021

Accepted: 22 June 2021

Published: 27 June 2021

Publisher's Note: MDPI stays neutral with regard to jurisdictional claims in published maps and institutional affiliations.

Copyright: (c) 2021 by the authors. Licensee MDPI, Basel, Switzerland. This article is an open access article distributed under the terms and conditions of the Creative Commons Attribution (CC BY) license (https:// creativecommons.org/licenses/by/ $4.0 /)$.

\begin{abstract}
This particular research was conducted with the aim of describing the impact of a rotating nanoliquid on an elasting surface. This specific study was carried out using a two-phase nanoliquid model. In this study engine oil is used as the base fluid, and two forms of nanoparticles are used, namely, titanium oxide and zinc oxide $\left(\mathrm{TiO}_{2}\right.$ and $\left.\mathrm{ZnO}\right)$. Using appropriate similarity transformations, the arising system of partial differential equations and the related boundary conditions are presented and then converted into a system of ordinary differential equations. These equations are numerically tackled using powerful techniques. Graphs for nanoparticle rotation parameter and volume fraction for both types of nanoparticles present the results for the velocity and heat transfer features. Quantities of physical significance are measured and evaluated, such as local heat flux intensity and local skin friction coefficients at the linear stretching surface. Numerical values for skin friction and local heat flux amplitude are determined in the presence of slip factor.
\end{abstract}

Keywords: rotating flow; linear stretching surface; partial slip; $\mathrm{ZnO}$ and $\mathrm{TiO}_{2}$ nanoparticles

\section{Introduction}

In different fields of industrial processing (e.g., material processing), the cooling of a metal plate in a cooling bath, the extrusion of plastic sheets, and the movement of a rotational fluid over enlarging surfaces are very common. Besides, revolving flow over a stretching surface is often used in glass driving and in the spinning phase of fibers. The heat transmission rate on the stretching surface is mutually linked to the quality of the final product, and it has been the subject of intensive research as it relates to the production process. Many researchers have concentrated on this particular field of study, bearing in mind this essential characteristic of the industrial process. By explaining the fundamental flow occurrence over an extending surface, Crane [1] took the initiative. Siddappa et al. [2] developed the concept of flow over a stretching surface in their study.

An initial research on three-dimensional (3D) movement over an enlarging flat surface was proposed by Wang [3]. Rajagopal et al. [4] described the flow of a viscoelastic fluid above a widening sheet. Wang et al. [5] discovered nanofluids' thermal conductivity in their work. Numerous researchers have followed this revolutionary work, in which a complete variety of physical complications were extracted. Nath and Kumari [6] operated the characteristics of MHD flow and temperature transfer flow on an extending sheet with a magnetic field. Narahari et al. [7] presented the notion of unstable MHD (magnetohydrodynamics) boundary layers in a rotational flow. Wang [8] primarily inspected the movement of a revolving fluid above a widening surface. Vajravelu et al. [9] conducted remarkable research on the arithmetic and logical clarifications of a nonlinear system resulting from a three-dimensional rotating flow. 
Nanofluids are a significant exploration target that is extremely respected as it is commonly used in a range of greatly progressive biomedical and scientific applications, such as nuclear reactors, microprocessor cooling, and radiators. Nanofluids are known to be highly effective cooling agents owing to their lesser molecular masses and extreme thermal conductivity. Buongiorno [10] studied the heat convection of nanofluids. Pak and Cho [11] explored the hydrodynamic and temperature transmission features of scattered fluids using metal oxide particles. Kakac et al. and Xuan et al. [12,13] studied heat transfer phenomena in nanofluids. Wong et al. [14] discussed the potential applications of nanofluids. Bachok et al. [15] expanded their experiments on a porous widening/shrinking surface for nanofluids. Kumari et al. [16] illuminated the intermittent spinning flow of an MHD power-law fluid above a broadening sheet. Zhou et al. [17] studied the wear effects and key oil constituents on low-viscosity engine oils.

Recently, research was carried out by Abbas et al. [18] to overcome the unsteady nanofluid magnetohydrodynamic flow through a porous medium past a moving plate in a revolving device, taking heat and mass transfer into account. Wróblewski et al. [19] discussed the configuration of an engine with increased isochoric pressure. Nadeem et al. [20] investigated heat transmission on an exponentially stretchable surface for water-based nanofluids. Bahiraei et al. [21] presented the competence of hybrid nanofluids. Bagherzadeh et al. [22] described the thermal conductivity of different nanofluids analytically instead of numerically. Ahmadi et al. [23] discussed the viscosity of a $\mathrm{CuO} /$ water nanofluid. Bagherzadeh et al. [24] discussed the efficacy of a hybrid nanofluid in a new microchannel. Bahmani et al. [25] studied the turbulent heat transfer in binary pipe exchangers. Indeed, many researchers have recently studied problems associated with nanofluids [26-33]. Noghrehabadi et al. [34] prescribed the slip effect at constant wall temperature. To the best of our understanding, no one has identified the joints of the rotation or the partial slip of the nanofluid above the extending surface. This type of flow could have potential uses in a range of current products and applications, including electronic chip cooling, hot rollers, plasma flow, and geothermal engineering.

The main aspect of this analysis is the numerical examination of the velocity and heat transfer properties of a rotating nanofluid above a linear extending surface using a partial slip effect. In this analysis, a physical model (i.e., a two-phase nanofluid physical model) is used to address this issue. Numerical outcomes and diagrams are obtained using the BVP4C technique. The effects of the dimensionless slip parameter $K$, volume fraction $\varphi$, and rotation parameter $\lambda$ on temperature, velocity, and skin friction coefficients are tabularized, graphically presented, and discussed. $\mathrm{ZnO}$ and $\mathrm{TiO}_{2}$ nanoparticles are used for this comparative study because they have higher and lower density, respectively, and to the best of our knowledge there has not yet been a demonstration of this combination with base engine oil.

\section{Mathematical Formulation}

The following Figure 1 describes the geometry of the problem. Consider viscous and incompressible engine oil-based nanofluid with constant density lying above a linearly stretching surface in region $z \geq 0$ which rotates along the $z$-axis with definite fixed angular velocity $\Omega$. Along the $x$-axis, two equal and opposing forces are exerted such that the surface is extended at a speed $U(x)$ which is directly proportional to the distance from the origin at $x=0$. The nanofluid is susceptible to slip-flow conditions and there are no external forces acting upon it. After neglecting the pressure gradient and the viscous dissipation, the arising energy and momentum equations [35] are as given below.

$$
\begin{gathered}
\frac{\partial u}{\partial x}+\frac{\partial v}{\partial y}+\frac{\partial w}{\partial z}=0 \\
u \frac{\partial u}{\partial x}+v \frac{\partial u}{\partial y}+w \frac{\partial u}{\partial z}=2 \Omega v+\frac{\mu_{n f}}{\rho_{n f}} \nabla^{2} u
\end{gathered}
$$




$$
\begin{gathered}
u \frac{\partial v}{\partial x}+v \frac{\partial v}{\partial y}+w \frac{\partial v}{\partial z}=-2 \Omega u+\frac{\mu_{n f}}{\rho_{n f}} \nabla^{2} v \\
u \frac{\partial w}{\partial x}+v \frac{\partial w}{\partial y}+w \frac{\partial w}{\partial z}=\frac{\mu_{n f}}{\rho_{n f}} \nabla^{2} w \\
u \frac{\partial T}{\partial x}+v \frac{\partial T}{\partial y}+w \frac{\partial T}{\partial z}=\alpha_{n f} \frac{\partial^{2} T}{\partial z^{2}} .
\end{gathered}
$$

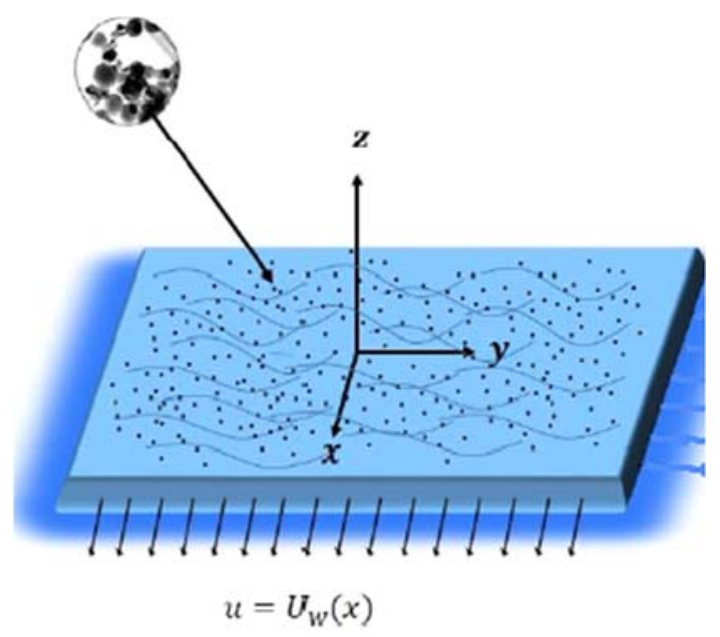

Figure 1. Geometry of the problem.

Here $u$ is the $x$ component, $v$ is the $y$ component, and $w$ is the $z$ component of velocity $\Omega ; \mu_{n f}$ is the fluid's dynamic viscosity, $\rho_{n f}$ is the nanofluid density, $\alpha_{n f}$ is the thermal diffusivity of the nanofluid, $T$ is the nanofluid temperature, $\left(\rho C_{p}\right)_{n f}$ is the volumetric heat capacity of the nanofluid, $\left(\rho C_{p}\right)_{f}$ is the volumetric heat capacity of the base fluid, and $\left(\rho C_{p}\right)_{s}$ is the volumetric heat capacity of the solid nanoparticles. All of these are related to the particle [35] volume fraction of nanoparticles $\varphi$ as follows.

$$
\left\{\begin{array}{c}
\rho_{n f}={ }_{\rho f}(1-\varphi)+\varphi \rho_{s}, \quad \mu_{n f}=\frac{\mu_{n}}{(1-\varphi)^{5 / 2}}, \quad\left(\rho C_{p}\right)_{n f}=\frac{k_{n f}}{\alpha_{n f}}, \\
\left(\rho C_{p}\right)_{n f}=\left(\rho C_{p}\right)_{f}(1-\varphi)+\varphi\left(\rho C_{p}\right)_{s^{\prime}}, \frac{k_{f}}{k_{n f}}=\frac{k_{s}+2 k_{f}+2 \varphi\left(k_{f}-k_{s}\right)}{k_{s}+2 k_{f}-2 \varphi\left(k_{f}-k_{s}\right)} .
\end{array}\right\}
$$

Here, $k_{f}$ is the thermal conductivity of the base fluid, $k_{s}$ is the thermal conductivity of the solid nanoparticles, $\rho_{s}$ is the density of the solid nanoparticles, and $\rho_{f}$ is the density of the base fluid.

The corresponding boundary conditions are given below.

$$
\left\{\begin{array}{c}
u(x, y, 0)-U=k v \frac{\partial u}{\partial z}(x, y, 0), \\
v(x, y, 0)=k v \frac{\partial v}{\partial z}(x, y, 0), \\
w(x, y, 0)=k v \frac{\partial w}{\partial z}(x, y, 0) .
\end{array}\right\}
$$

Here $U=a x$ is the velocity of the surface, " $a$ " is the proportionality constant representing the surface extension rate, $k$ is the slip distance, and $v$ is the base fluid's kinematic viscosity.

\section{Transformation Methodology}

By using the following similarity transformation [35], that is,

$$
\left\{\begin{array}{c}
u=a x f^{\prime}(\eta), v=a x h(\eta), w=-\sqrt{a v} f(\eta), \\
\eta=z \sqrt{\frac{a}{v}}, \theta(\eta)=\frac{T-T_{\infty}}{T-T_{w}} .
\end{array}\right\}
$$


Here $\eta$ is the match space parameter, and $T_{\infty}$ and $T_{w}$ are the temperatures at the wall and free streams, respectively.

By using Equation (8) in Equation (1), we observe that it remains identical (i.e., mass remains conserved). Equations (2)-(5), using values from Equations (6) and (8), are transformed into ordinary differential equations as follows.

$$
\begin{gathered}
\frac{1}{(1-\varphi)^{5 / 2}} f^{\prime \prime \prime}+\left(1-\varphi+\varphi \frac{\rho_{s}}{\rho_{b f}}\right)\left(f f^{\prime \prime}-f^{\prime 2}+2 h \lambda\right)=0 \\
\frac{1}{(1-\varphi)^{5 / 2}} h^{\prime \prime}+\left(1-\varphi+\varphi \frac{\rho_{s}}{\rho_{b f}}\right)\left(f h^{\prime}-h f^{\prime}-2 \lambda f^{\prime}\right)=0, \\
\frac{k_{n f}}{k_{f}} \theta^{\prime \prime}(\eta)+\operatorname{Pr}\left[1-\varphi+\varphi \frac{\left(\rho C_{p}\right)_{s}}{\left(\rho C_{p}\right)_{f}}\right] f \theta^{\prime}(\eta)=0
\end{gathered}
$$

In these Equations (9)-(11), $\lambda$ is the rotation parameter and $\operatorname{Pr}$ denotes Prandtl number which is defined as

$$
\lambda=\frac{\Omega}{a}, \operatorname{Pr}=\frac{\left(\mu C_{p}\right)_{f}}{k_{f}}
$$

From the above-given equations, $\Omega$ is the fixed angular fluid's velocity. the form

Using Equation (8) in Equation (7), the corresponding boundary conditions take

$$
\left\{\begin{array}{c}
f(0)=0, f^{\prime}(0)=1+K f^{\prime \prime}(0), f^{\prime}(\infty)=0, \\
h(0)=K h^{\prime}(0), h(\infty)=0, \theta(0)=1, \quad \theta(\infty)=0 .
\end{array}\right\}
$$

Here $K=K \sqrt{a v}$ is the slip parameter.

\section{Method of Solution}

The combined system of ordinary differential Equations (9)-(11) is vastly non-linear and has been tackled numerically using the BVP4C technique built-in MATLAB. The procedure transforms the leading differential equations into an ordinary differential equation system of the first order that is iteratively addressed. Numerical tables and graphical results are acquired using the very capable tool MATLAB. The physical quantities we evaluate are the skin frictions $C f_{x}, C f_{y}$ along the $x$-axis and $y$-axis respectively and the Nusselt number $\mathrm{Nu}$, where

$$
\left\{\begin{array}{c}
C f_{x}=\frac{\tau_{x z}}{\rho(a x)^{2}}, \\
C f_{y}=\frac{\tau_{y z}}{\rho(a x)^{2}}, \\
N u=\frac{x q_{w}}{k_{f}\left(T-T_{\infty}\right)} .
\end{array}\right\}
$$

Here $q_{w}$ is the heat flux, and $\tau_{x z}$ and $\tau_{y z}$ [36] are shear stresses of the surface given by

$$
\left\{\begin{array}{c}
\tau_{x z}=\mu_{n f}\left(\frac{\partial u}{\partial z}+\frac{\partial w}{\partial x}\right)_{z=0^{\prime}} \\
\tau_{y z}=\mu_{n f}\left(\frac{\partial v}{\partial z}+\frac{\partial w}{\partial y}\right)_{z=0^{\prime}} \\
q_{w}=-k_{n f}\left(\frac{\partial T}{\partial z}\right)_{z=0}
\end{array}\right\}
$$

By substituting Equations (8) and (15) in Equation (14), we get

$$
\left\{\begin{array}{c}
\left(R e_{x}\right)^{1 / 2} C f_{x}=\frac{1}{(1-\varphi)^{5 / 2}} f^{\prime \prime}(0), \\
\left(R e_{x}\right)^{1 / 2} C f_{y}=\frac{1}{(1-\varphi)^{5 / 2}} h^{\prime}(0), \\
\left(R e_{x}\right)^{-1 / 2} N u=\frac{-k_{n f}}{k_{f}} \theta^{\prime}(0),
\end{array}\right\}
$$


where the local Reynolds number is $R e_{x}=\frac{(a x)_{x}}{v_{f}}$, skin frictions $\frac{1}{(1-\varphi)^{5 / 2}} f^{\prime \prime}(0), \frac{1}{(1-\phi)^{5 / 2}} h^{\prime}(0)$, and heat flux $\frac{-k_{n f}}{k_{f}} \theta^{\prime}(0)$ are presented together for both nanofluids via different variations of volume fraction $\varphi$, rotation parameter $\lambda$, and slip parameter $K$.

\section{Results and Graphical Interpretation}

This section addresses the effect of different physical constraints (e.g., rotation parameter $\lambda$, volume fraction $\varphi$, and slip constraint $K$ ) on the temperature and velocity profiles of the $\mathrm{TiO}_{2}$ and $\mathrm{ZnO}$ engine oil nanofluids. Graphical outcomes are presented to determine their real effect on these physical quantities. The following figures are plotted for this purpose.

The plots in Figure $2 \mathrm{a}-\mathrm{d}$ are given to determine the effect on the velocity profile $f^{\prime}(\eta)$ of the rotation parameter $\lambda$ and slip parameter $K$ for $\mathrm{ZnO}$ and $\mathrm{TiO}_{2}$ engine oil nanofluids. In Figure $2 \mathrm{a}, \mathrm{b}$ it can be seen that an increase of the rotation parameter $\lambda$ results in a decreasing behavior of the velocity profile $f^{\prime}(\eta)$ for both nanoliquids. This is because the existence of the slip velocity factor overcomes the motion of the fluid associated with its increasing rotation. By increasing the slip parameter $K$, Figure $2 \mathrm{c}$,d shows that the horizontal velocity $f^{\prime}(\eta)$ increases for both $\mathrm{ZnO}$ and $\mathrm{TiO}_{2}$ engine oil nanofluids. This results from the existence of slip - the velocity of the fluid near the surface does not remain similar to the extension of the surface. Therefore, slip velocity also increases by increasing the slip parameter $K$. This subsequently reduces the fluid velocity, since in this case the drawing of the extending surface can be partially explained by the existence of the slip factor. As the slip factor $K$ increases, the frontier layer thickness decreases. However, it is fascinating to know that the insertion of $\mathrm{ZnO}$ nanoparticles leads to a decrement in the velocity profile $f^{\prime}(\eta)$, and the behavior is opposite in the case of $\mathrm{TiO}_{2}$ nanoparticles (Figure $2 \mathrm{c}, \mathrm{d}$ ). In Figure $2 \mathrm{a}-\mathrm{d}$ the lines on the graph are very close because of the base fluid. Engine oil has a higher viscosity than that of water. So, when rotation starts there is a very small change in the velocity profile $f^{\prime}(\eta)$, and when the rotation rate increases, the velocity lines separate. Similar arguments can be made regarding the slip parameter $\mathrm{ZnO}$. The influence of the partial slip factor $K$ and rotation constraint $\lambda$ on the vertical velocity constituent $h(\eta)$ is presented in Figure 3a-d for both $\mathrm{ZnO}$ and $\mathrm{TiO}_{2}$ engine oil nanofluids. Figure $3 \mathrm{a}$,b shows that the vertical velocity $h(\eta)$ decays with increasing rotation constraint $\lambda$ for both $\mathrm{ZnO}$ and $\mathrm{TiO}_{2}$ engine oil nanofluids. Additionally, $h(\eta)$ decreases as the slip parameter $K$ increases near the wall. This specific behavior can be noted for both $\mathrm{ZnO}$ and $\mathrm{TiO}_{2}$ engine oil nanofluids (Figure 3c,d). In Figure $4 \mathrm{a}-\mathrm{d}$, it can be determined that the velocity profile $f(\eta)$ increases with increasing slip parameter $K$ and decreases with increasing rotation parameter $\lambda$. Furthermore, with the addition of $\mathrm{ZnO}$ nanoparticles, the velocity profile $f(\eta)$ decreases (Figure $4 \mathrm{a}, \mathrm{c}$ ), and it increases with the addition of $\mathrm{TiO}_{2}$ nanoparticles (Figure $4 \mathrm{~b}, \mathrm{~d}$ ). A distinction in the temperature profile $\theta(\eta)$ with varying slip parameter $K$ and volume fraction $\varphi$ for $\mathrm{ZnO}$ and $\mathrm{TiO}_{2}$ engine oil nanofluids can be seen in Figure $5 \mathrm{a}-\mathrm{d}$. We can determine from Figure $5 \mathrm{a}, \mathrm{b}$ that the temperature profile $\theta(\eta)$ significantly increases with increasing volume fraction $\varphi$ and it decreases as slip parameter $K$ increases (Figure $5 c, d$ ). It is interesting to note that the rotation parameter $\lambda$ does not affect the temperature profile $\theta(\eta)$. 


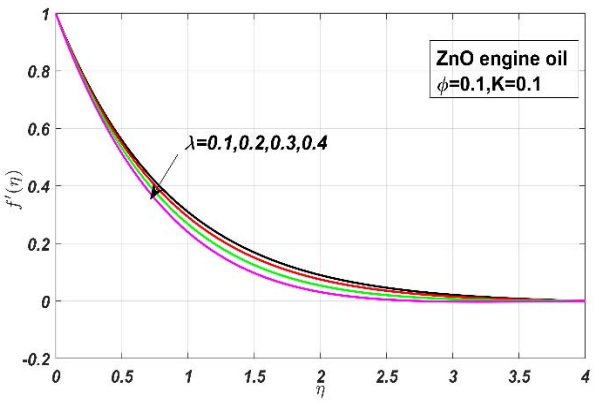

(a)

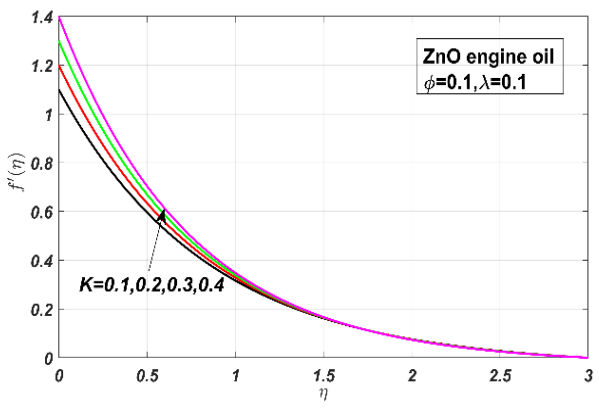

(c)

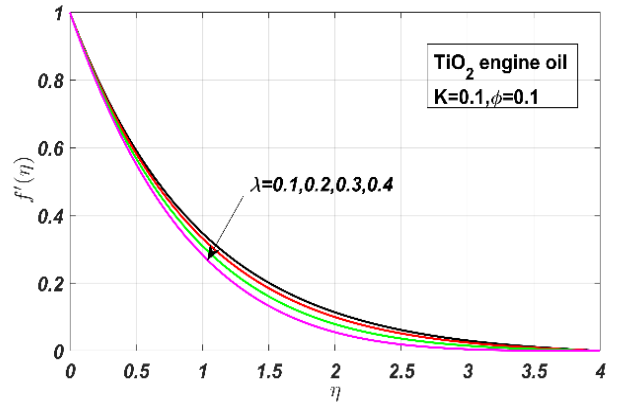

(b)

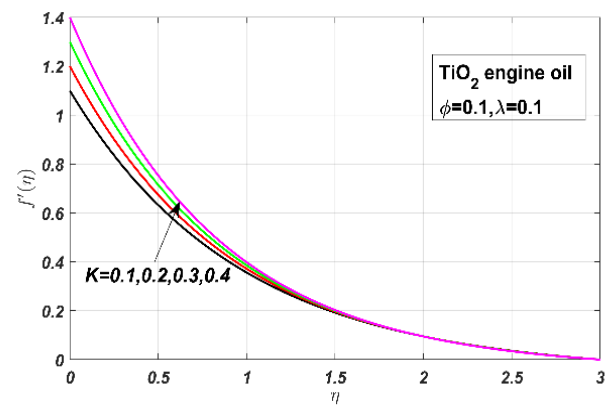

(d)

Figure 2. The impact of rotation parameter $\lambda(\mathbf{a}, \mathbf{b})$ and slip parameter $K(\mathbf{c}, \mathbf{d})$ on the velocity profile $f^{\prime}(\eta)$ for $\mathrm{ZnO}$ and $\mathrm{TiO}_{2}$ engine oil nanofluids.

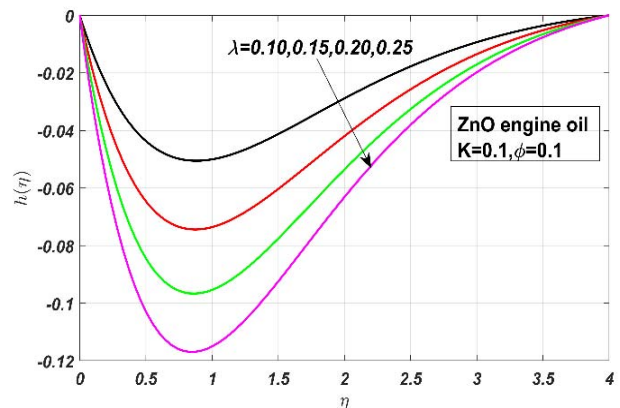

(a)

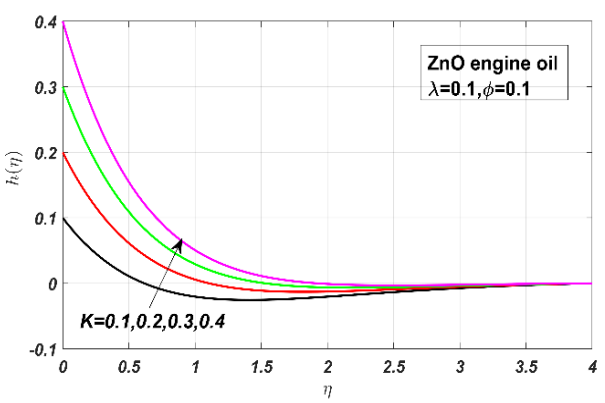

(c)

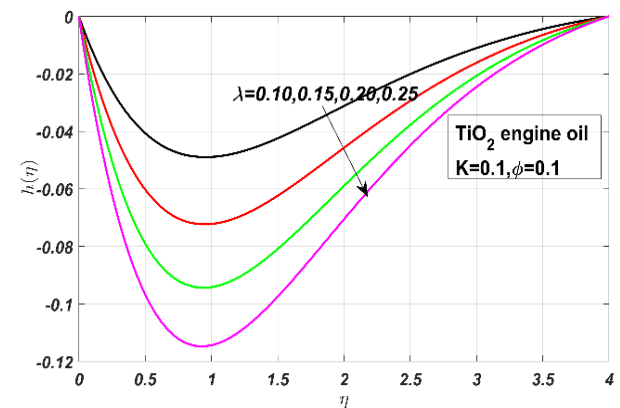

(b)

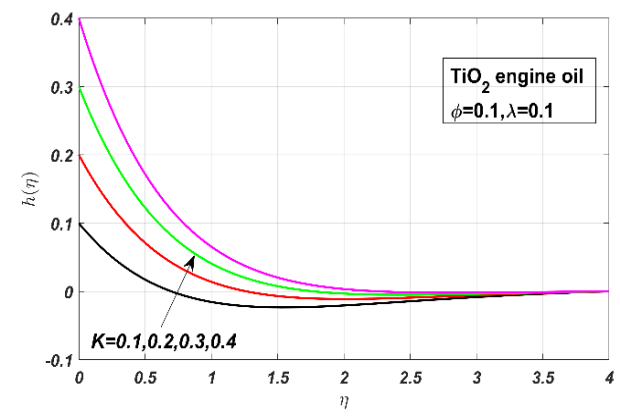

(d)

Figure 3. The impact of rotation parameter $\lambda(\mathbf{a}, \mathbf{b})$ and slip parameter $K(\mathbf{c}, \mathbf{d})$ on the velocity profile $h(\eta)$ for $\mathrm{ZnO}$ and $\mathrm{TiO}_{2}$ engine oil nanofluids. 


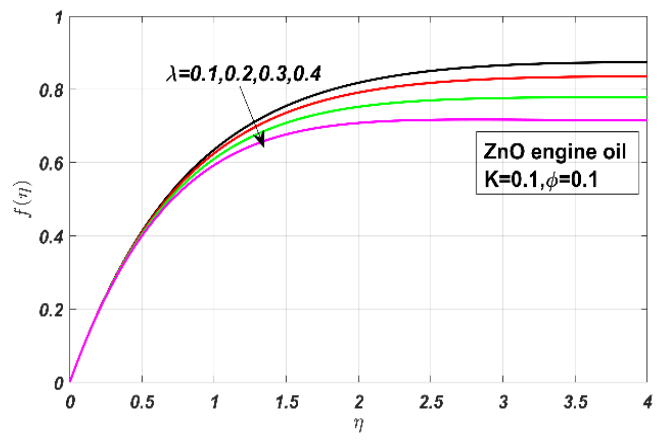

(a)

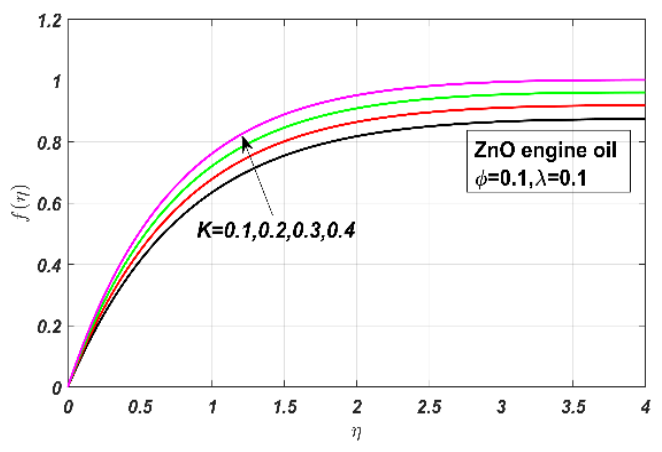

(c)

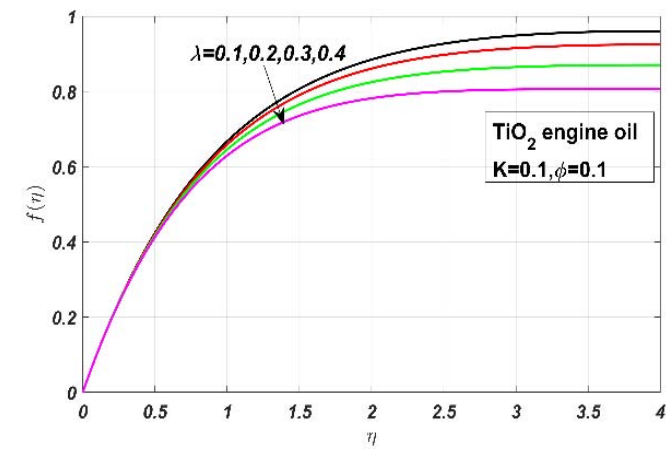

(b)

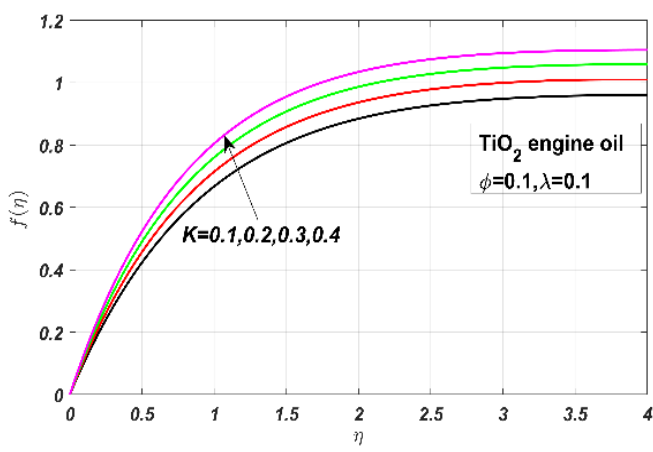

(d)

Figure 4. The impact of rotation parameter $\lambda(\mathbf{a}, \mathbf{b})$ and slip parameter $K(\mathbf{c}, \mathbf{d})$ on the velocity profile $f(\eta)$ for $\mathrm{ZnO}$ and $\mathrm{TiO}_{2}$ engine oil nanofluids.

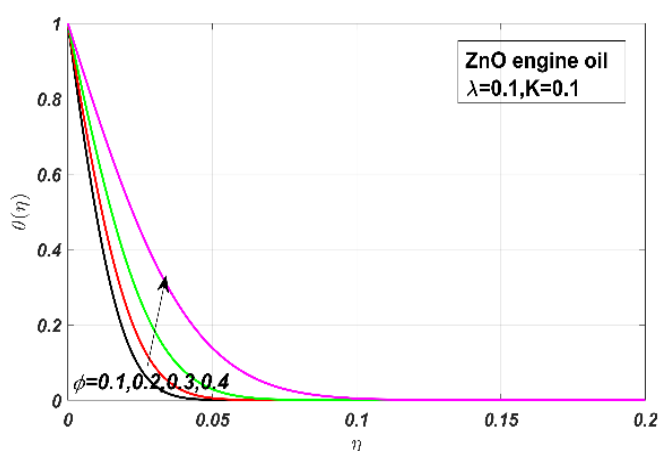

(a)

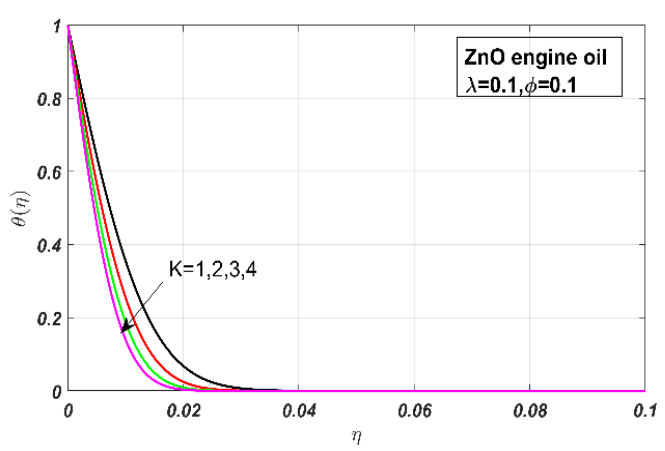

(c)

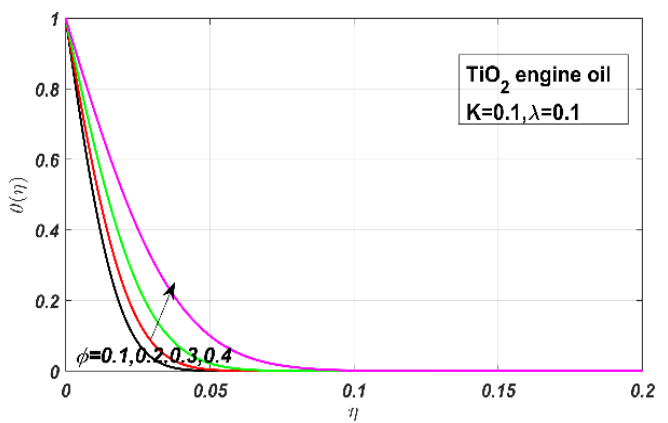

(b)

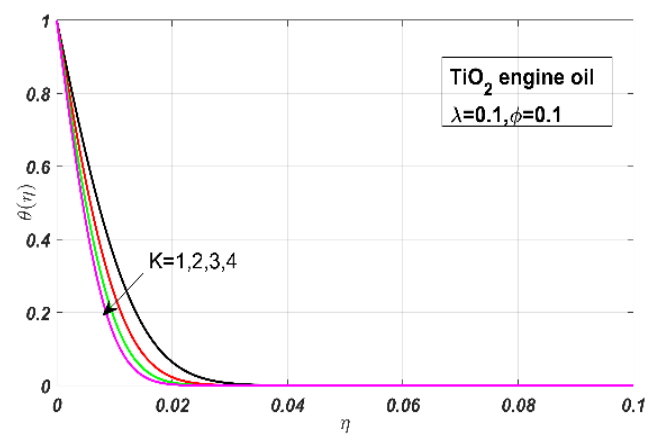

(d)

Figure 5. The impact of volume fraction $\varphi(\mathbf{a}, \mathbf{b})$ and slip parameter $K(\mathbf{c}, \mathbf{d})$ on the temperature profile $f(\eta)$ for $\mathrm{ZnO}$ and $\mathrm{TiO}_{2}$ engine oil nanofluids. 
To verify the dissimilarities of fascinating physical constraints on the local skin friction coefficient and local Nusselt number, the following tables are presented. Table 1 represents the thermophysical properties of the nanofluid components. Table 2 illustrates that for a specific value of slip parameter $K$ and fixed volume fraction $\varphi$, the local skin friction (i.e., $\left.\frac{1}{(1-\varphi)^{5 / 2}} f^{\prime \prime}(0)\right)$ increases with increasing rotation parameter $\lambda$. The trend is similar if we specify the value of $\lambda$ and change $\varphi$. However, for a permanent pair $(\varphi, \lambda)$, the absolute skin friction owing to $\mathrm{ZnO}$ is permanently higher than that owing to $\mathrm{TiO}_{2}$, which can be explained by the comparatively higher density of $\mathrm{ZnO}$ particles. Local skin friction (i.e., $\left.\frac{1}{(1-\varphi)^{5 / 2}} h^{\prime}(0)\right)$ is calculated for different pairs of $(\varphi, \lambda)$. It can be seen from the tables that an increase in $\varphi$ and $\lambda$ increases the skin friction along the $y$-axis. Remarkably, for any pair $(\phi, \lambda)$, the skin friction due to $\mathrm{ZnO}$ is higher than that for other nanofluids. Similarly, the local heat flux $\left(\frac{-k_{n f}}{k_{f}} \theta(0)\right)$ decreases as the rotation parameter $\lambda$ increases. Meanwhile, increasing the nanoparticle volume fraction $\varphi$ results in an increased heat transfer rate due to the greater thermal conductivity and lower specific heat of the nanofluid as compared to the base fluid. Further, for any fixed pair $(\varphi, \lambda)$, the local heat flux due to $\mathrm{ZnO}$ is always higher than that due to $\mathrm{TiO}_{2}$. his is because $\mathrm{TiO}_{2}$ has a lower thermal conductivity as compared with $\mathrm{ZnO}$, which allows for the rapid removal of heat. In Table 3, the previously published data is given and compared to the present results. It is interesting to observe that the present values for $\mathrm{ZnO}$ are in better agreement with those obtained previously.

Table 1. Thermo-physical properties of nanoparticles $\left(\mathrm{ZnO}, \mathrm{TiO}_{2}\right)$ and base fluid engine oil.

\begin{tabular}{cccc}
\hline Component & Density $(\boldsymbol{\rho})$ & Thermal Conductivity $(\boldsymbol{K})$ & Specific Heat $\left(\boldsymbol{C}_{\boldsymbol{p}}\right)$ \\
\hline $\mathrm{ZnO}$ & 7140 & 120 & 389 \\
\hline $\mathrm{TiO}_{2}$ & 4250 & 8.96 & 686.2 \\
\hline Engine oil & 884 & 0.144 & 1910 \\
\hline
\end{tabular}

Table 2. Variation of distinct parameters on $C f_{x}$ ( skin friction along $x$-axis) (a,b), $C f_{y}$ (skin friction along $y$-axis) (c, d) and Nusselt number $N u_{x}(\mathrm{e}, \mathrm{f})$.

(a) $\mathrm{TiO}_{2}$ engine oil nanofluid for $\mathrm{Pr}=6450$

\begin{tabular}{ccccc}
\hline$\varphi$ & $\lambda=0.0$ & $\lambda=0.5$ & $\lambda=1.0$ & $\lambda=2.0$ \\
\hline 0.0 & 1.0000 & 1.1384 & 1.3252 & 1.6523 \\
\hline 0.01 & 1.0291 & 1.1715 & 1.3635 & 1.7004 \\
\hline 0.1 & 1.3138 & 1.4956 & 1.7408 & 2.1708 \\
\hline 0.2 & 1.6991 & 1.9342 & 2.2513 & 2.8075 \\
\hline
\end{tabular}

(b) $\mathrm{ZnO}$ engine oil nanofluid for $\mathrm{Pr}=6450$

\begin{tabular}{ccccc}
\hline$\varphi$ & $\lambda=0.0$ & $\lambda=0.5$ & $\lambda=1.0$ & $\lambda=2.0$ \\
\hline 0.0 & 1.0000 & 1.1388 & 1.3255 & 1.6529 \\
\hline 0.01 & 1.0525 & 1.1982 & 1.3946 & 1.7389 \\
\hline 0.1 & 1.5290 & 1.7408 & 2.0262 & 2.5265 \\
\hline 0.2 & 2.1282 & 2.4228 & 2.8199 & 3.5164 \\
\hline
\end{tabular}


Table 2. Cont.

(c) $\mathrm{TiO}_{2}$ engine oil nanofluid for $\mathrm{Pr}=6450$.

\begin{tabular}{ccccc}
\hline$\varphi$ & $\lambda=0.0$ & $\lambda=0.5$ & $\lambda=1.0$ & $\lambda=2.0$ \\
\hline 0.0 & 0.0000 & 0.5130 & 0.8372 & 1.2873 \\
\hline 0.01 & 0.0000 & 0.5277 & 0.8614 & 1.3247 \\
\hline 0.1 & 0.0000 & 0.6737 & 1.0998 & 1.6912 \\
\hline 0.2 & 0.0000 & 0.8713 & 1.4223 & 2.1872 \\
\hline \multicolumn{5}{c}{$(\mathrm{d})$ ZnO engine oil nanofluid for $P r=6450}$. \\
\hline 0.0 & $\lambda=0.0$ & $\lambda=0.5$ & $\lambda=1.0$ & $\lambda=2.0$ \\
\hline 0.1 & 0.0000 & 0.5132 & 0.8375 & 1.3243 \\
\hline 0.2 & 0.0000 & 0.5401 & 0.8817 & 1.3599 \\
\hline & 0.0000 & 0.7844 & 1.2818 & 1.9691 \\
\hline
\end{tabular}

(e) $\mathrm{TiO}_{2}$ engine oil nanofluid for $\mathrm{Pr}=6450$.

\begin{tabular}{ccccc}
\hline$\varphi$ & $\lambda=0.0$ & $\lambda=0.5$ & $\lambda=1.0$ & $\lambda=2.0$ \\
\hline 0.0 & 1.7710 & 1.7257 & 1.6603 & 1.5335 \\
\hline 0.01 & 1.7863 & 1.7393 & 1.6716 & 1.5402 \\
\hline 0.1 & 1.9265 & 1.8648 & 1.7752 & 1.6033 \\
\hline 0.2 & 2.0932 & 2.01254 & 1.9025 & 1.6898 \\
\hline \multicolumn{5}{c}{$(\mathrm{f})$ ZnO engine oil nanofluid for $P r=6450}$. \\
\hline 0.0 & $\lambda=0.0$ & $\lambda=0.5$ & $\lambda=1.0$ & $\lambda=2.0$ \\
\hline 0.01 & 1.7923 & 1.7294 & 1.6802 & 1.5340 \\
\hline 0.1 & 1.8201 & 1.7726 & 1.6723 & 1.5345 \\
\hline 0.2 & 1.9823 & 1.8932 & 1.7832 & 1.5521 \\
\hline
\end{tabular}

Table 3. Comparison of absolute values of $f^{\prime \prime}(0)$ and $h^{\prime}(0)$.

\begin{tabular}{cccccccccccc}
\hline & \multicolumn{2}{c}{ Wang [8] } & \multicolumn{2}{c}{ Nazar et al. [37] } & \multicolumn{2}{c}{ Kumari et al. [6] } & \multicolumn{2}{c}{ Hayat et al. [36] } & \multicolumn{2}{c}{ Present Results } \\
\hline$\lambda$ & $\boldsymbol{f}^{\prime \prime}(0)$ & $\boldsymbol{h}^{\prime}(0)$ & $\boldsymbol{f}^{\prime \prime}(0)$ & $\boldsymbol{h}^{\prime}(0)$ & $\boldsymbol{f}^{\prime \prime}(0)$ & $\boldsymbol{h}^{\prime}(0)$ & $\boldsymbol{f}^{\prime}(0)$ & $\boldsymbol{h}^{\prime}(0)$ & $\boldsymbol{f}^{\prime}(0)$ & $\boldsymbol{h}^{\prime}(0)$ \\
\hline 0.0 & 1.0000 & 0.0000 & 1.000 & 0.0000 & 0.9999 & 0.0000 & 1.0000 & 0.0000 & 1.0000 & 0.0000 \\
\hline 0.5 & 1.1384 & 0.5128 & 1.1384 & 0.5128 & 1.1382 & 0.5128 & 1.1383 & 0.5127 & 1.1385 & 0.5130 \\
\hline 1.0 & 1.3250 & 0.8371 & 1.3250 & 0.8371 & 1.3251 & 0.8371 & 1.3250 & 0.8370 & 1.3252 & 0.8372 \\
\hline 2.0 & 1.6523 & 1.2873 & 1.6523 & 1.2873 & 1.6535 & 1.2873 & 1.6523 & 1.2872 & 1.6525 & 1.2874 \\
\hline
\end{tabular}

\section{Graphs of Skin Friction and Nusselt Number}

Figure 6 shows the impact of rotation parameter on skin friction along the $x$-axis. Figure 7 demonstrated the influence of rotation parameter on skin friction along the $y$-axis.

Figure 8 described the effect of rotation parameter on Nusselt number. 


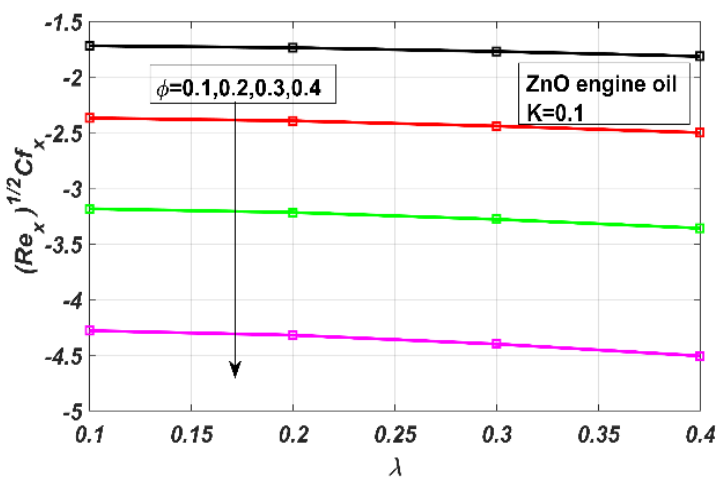

(a)

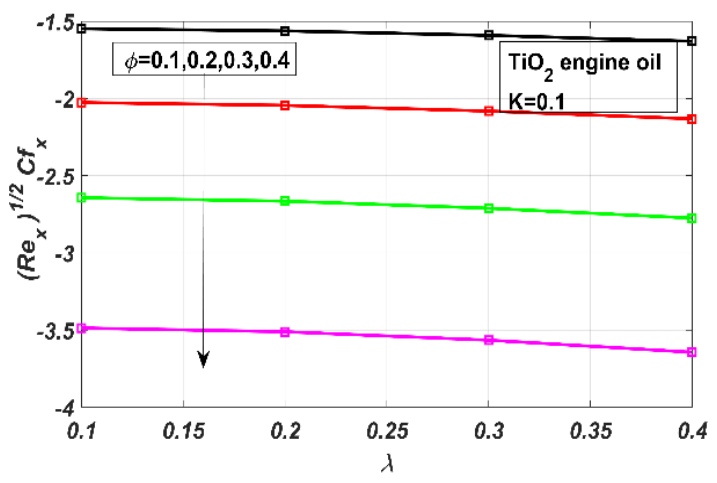

(b)

Figure 6. The impact of rotation parameter $\lambda(\mathbf{a}, \mathbf{b})$ on skin friction along the $x$-axis.

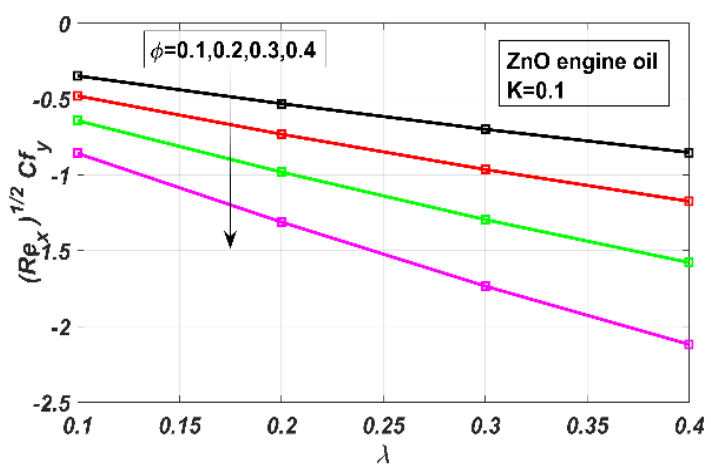

(a)

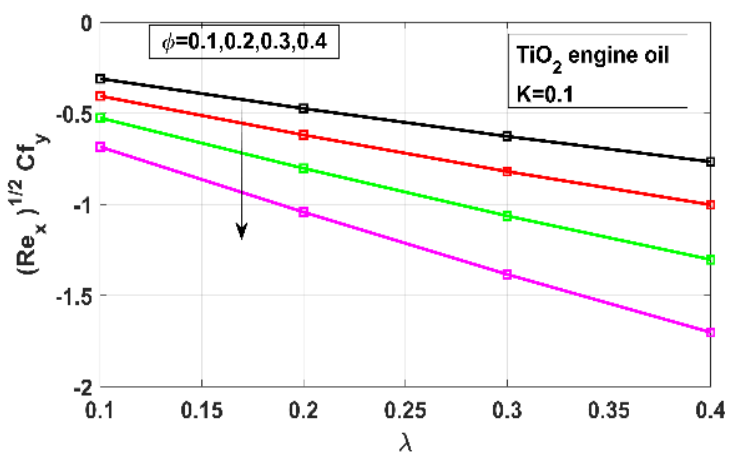

(b)

Figure 7. The impact of rotation parameter $\lambda(\mathbf{a}, \mathbf{b})$ on skin friction along the $y$-axis.

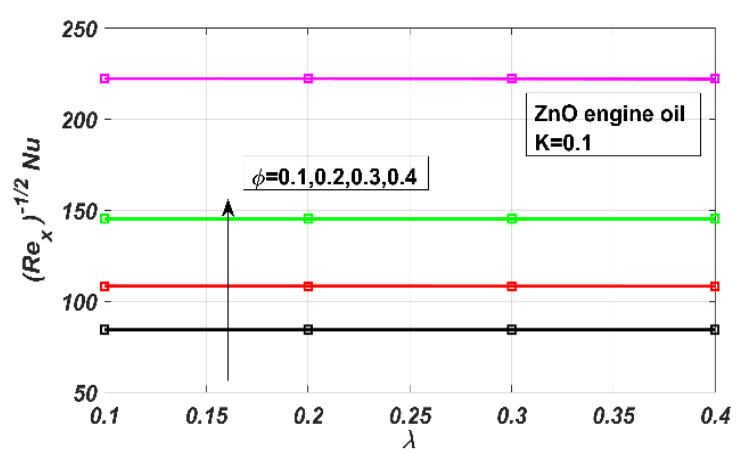

(a)

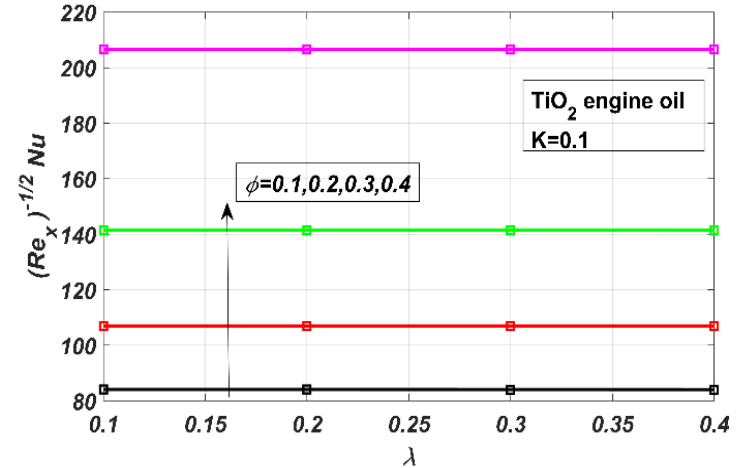

(b)

Figure 8. The impact of rotation parameter $\lambda(\mathbf{a}, \mathbf{b})$ on the Nusselt Number $(N u)$.

\section{Conclusions}

In this study, the partial slip effect of a rotating engine-oil-based nanofluid's flow on a linear extending surface is thoroughly analyzed. Further deductions can be made as follows:

1. Partial slip increases and rotation decreases the velocity of both nanofluids.

2. The numerical values of skin friction for $\varphi=0$ in the case of a viscous fluid match those already published, confirming the accuracy of the present results.

3. The temperature of the nanofluid decreases with increasing partial slip. 
4. Volume fraction $\varphi$ and rotation $\lambda$ both increase the temperatures of both nanofluids, but this effect is more prominent in the case of $\mathrm{ZnO}$ as compared to $\mathrm{TiO}_{2}$ engine oil nanofluid.

5. Local skin resistances increase with increasing nanoparticle angular velocity and particle volume fraction. This rise is higher in the case of the $\mathrm{ZnO}$-based nanofluid.

6. The entire heat transfer of the surface increases with increasing volume fraction and decreases with increasing rotation.

7. The $\mathrm{ZnO}$-based engine oil is proved to be a good heat carrier as compared to the $\mathrm{TiO}_{2}$ engine oil nanofluid.

Author Contributions: Conceptualization, A.H. (Azad Hussain); methodology, writing-original draft preparation, M.A.; software, writing-review A.R.; investigation A.H. (Ali Hassan); formal analysis, writing-review, S.K.E.; visualization, validation, N.A.A. All authors have read and agreed to the published version of the manuscript.

Funding: This research was funded by Taif University Researchers Supporting Project number (TURSP-2020/247), Taif University, Taif, Saudi Arabia.

Data Availability Statement: The data presented in this study are available on request from the corresponding authors M.A. and A.R.

Acknowledgments: Taif University Researchers Supporting Project number (TURSP-2020/247), Taif University, Taif, Saudi Arabia.

Conflicts of Interest: The authors declare no conflict of interest.

\section{Nomenclature}

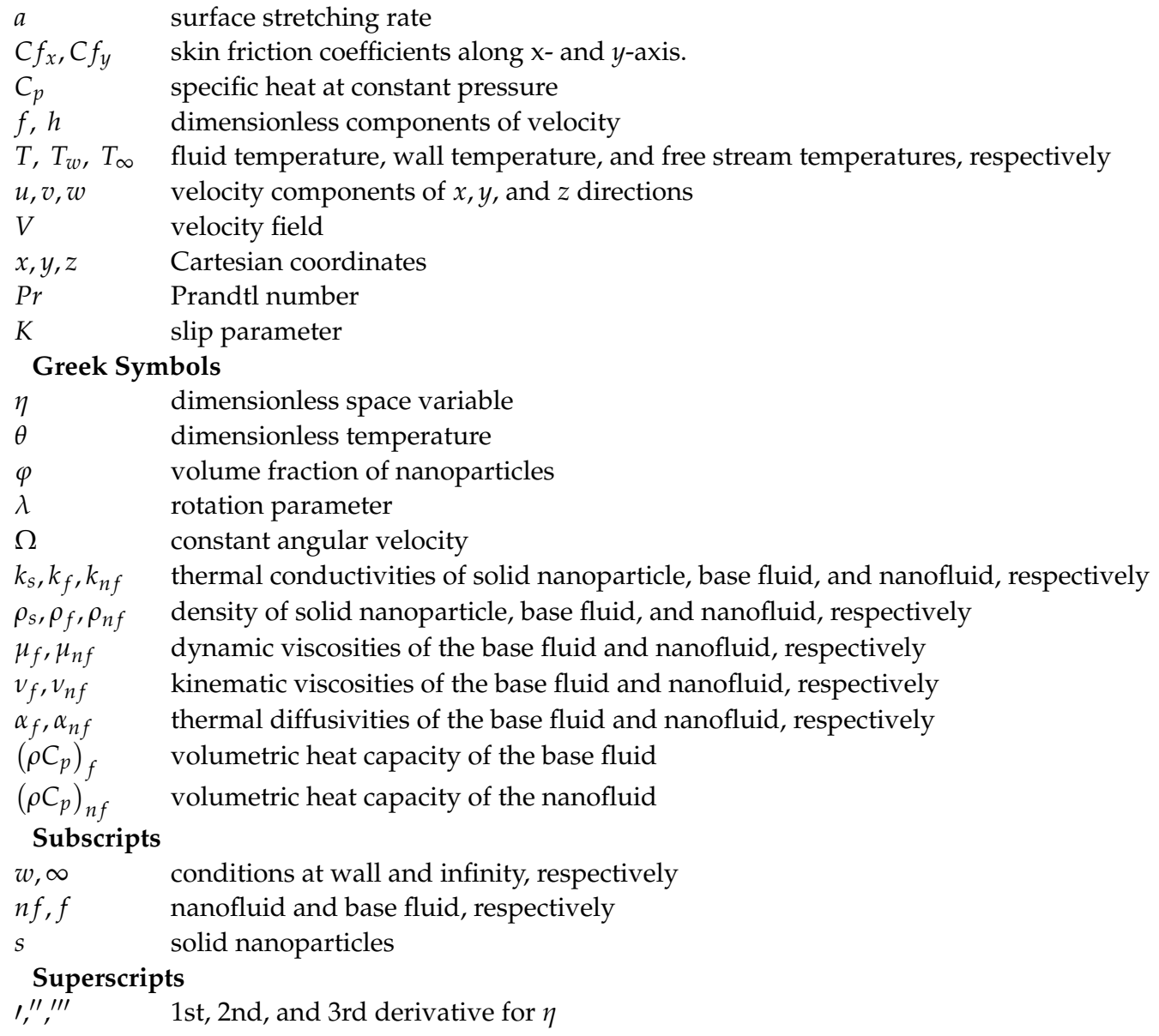




\section{References}

1. Crane, L.J. Flow past a stretching plate. Z. Angew. Math. Physik 1970, 21, 645-647. [CrossRef]

2. Siddappa, B. Rivlin-ericksen fluid flow past a stretching plate. Kyungpook Mathemat. J. 1980, 20, $267-272$.

3. Wang, C.Y. The three-dimensional flow due to a stretching flat surface. Phys. Fluids 1984, 27, 1915. [CrossRef]

4. Rajagopal, K.R.; Na, T.-Y.; Gupta, A.S. Flow of a viscoelastic fluid over a stretching sheet. Rheol. Acta 1984, 23, 213-215. [CrossRef]

5. Wang, X.; Xu, X.; Choi, S.U.S. Thermal Conductivity of Nanoparticle-Fluid Mixture. J. Thermophys. Heat Transf. 1999, 13, 474-480. [CrossRef]

6. Kumari, M.; Nath, G. Transient rotating flow over a moving surface with a magnetic field. Int. J. Heat Mass Transf. 2005, 48, 2878-2885. [CrossRef]

7. Narahari, M.; Debnath, L. Unsteady magnetohydrodynamic free convection flow past an accelerated vertical plate with constant heat flux and heat generation or absorption. ZAMM J. Appl. Math. Mech./Z. Angew. Math. Mech. 2012, 93, 38-49. [CrossRef]

8. Wang, C.Y. Stretching a surface in a rotating fluid. Z. Angew. Math. Physik 1988, 39, 177-185. [CrossRef]

9. Vajravelu, K.; Kumar, B. Analytical and numerical solutions of a coupled non-linear system arising in a three-dimensional rotating flow. Int. J. Non Linear Mech. 2004, 39, 13-24. [CrossRef]

10. Buongiorno, J. Convective Transport in Nanofluids. J. Heat Transf. 2006, 128, 240-250. [CrossRef]

11. Pak, B.C.; Cho, Y.I. Hydrodynamic and heat transfer study of dispersed fluids with submicron metallic oxide particles. Exp. Heat Transf. 1998, 11, 151-170. [CrossRef]

12. Kakaç, S.; Pramuanjaroenkij, A. Review of convective heat transfer enhancement with nanofluids. Int. J. Heat Mass Transf. 2009, 52, 3187-3196. [CrossRef]

13. Xuan, Y.; Li, Q. Heat transfer enhancement of nanofluids. Int. J. Heat Fluid Flow 2000, 21, 58-64. [CrossRef]

14. Wong, K.V.; De Leon, O. Applications of Nanofluids: Current and Future. Adv. Mech. Eng. 2010, 2, 1-12. [CrossRef]

15. Bachok, N.; Ishak, A.; Pop, I. Stagnation-point flow over a stretching/shrinking sheet in a nanofluid. Nanoscale Res. Lett. 2011, 6, 623. [CrossRef] [PubMed]

16. Kumari, M.; Grosan, T.; Pop, I. Rotating flow of power-law fluids over a stretching surface. Tech. Mech. Sci. J. Fundam. Appl. Eng. Mech. 2006, 26, 11-19.

17. Zhou, Y.; Pan, G.; Shi, X.; Zhang, S.; Gong, H.; Luo, G. Effects of ultra-smooth surface atomic step morphology on chemical mechanical polishing (CMP) performances of sapphire and SiC wafers. Tribol. Int. 2015, 87, 145-150. [CrossRef]

18. Abbas, W.; Magdy, M.M. Heat and Mass Transfer Analysis of Nanofluid Flow Based on $\mathrm{Cu}_{2} \mathrm{Al}_{2} \mathrm{O}_{3}$, and $\mathrm{TiO}_{2}$ over a Moving Rotating Plate and Impact of Various Nanoparticle Shapes. Math. Probl. Eng. 2020, 2020, 9606382. [CrossRef]

19. Wróblewski, P.; Iskra, A. Problems of Reducing Friction Losses of a Piston-Ring-Cylinder Configuration in a Combustion Piston Engine with an Increased Isochoric Pressure Gain; SAE Technical Paper 2020-01-2227; SAE: Warrendale, PA, USA, 2020.

20. Nadeem, S.; Haq, R.U.; Khan, Z.H. Heat transfer analysis of water-based nanofluid over an exponentially stretching sheet. Alex. Eng. J. 2014, 53, 219-224. [CrossRef]

21. Bahiraei, M.; Jamshidmofid, M.; Goodarzi, M. Efficacy of a hybrid nanofluid in a new microchannel heat sink equipped with both secondary channels and ribs. J. Mol. Liq. 2019, 273, 88-98. [CrossRef]

22. Bagherzadeh, S.A.; D'Orazio, A.; Karimipour, A.; Goodarzi, M.; Bach, Q.-V. A novel sensitivity analysis model of EANN for F-MWCNTs-Fe3O4/EG nanofluid thermal conductivity: Outputs predicted analytically instead of numerically to more accuracy and less costs. Phys. A Stat. Mech. Appl. 2019, 521, 406-415. [CrossRef]

23. Ahmadi, M.H.; Mohseni-Gharyehsafa, B.; Ghazvini, M.; Goodarzi, M.; Jilte, R.; Kumar, R. Comparing various machine learning approaches in modeling the dynamic viscosity of $\mathrm{CuO} /$ water nanofluid. J. Therm. Anal. Calorim. 2019, 139, 2585-2599. [CrossRef]

24. Bagherzadeh, S.A.; Jalali, E.; Sarafraz, M.; Akbari, O.A.; Karimipour, A.; Goodarzi, M.; Bach, Q.-V. Effects of magnetic field on micro cross jet injection of dispersed nanoparticles in a microchannel. Int. J. Numer. Methods Heat Fluid Flow 2019, 30, $2683-2704$. [CrossRef]

25. Bahmani, M.H.; Sheikhzadeh, G.; Zarringhalam, M.; Akbari, O.A.; Alrashed, A.A.; Shabani, G.A.S.; Goodarzi, M. Investigation of turbulent heat transfer and nanofluid flow in a double pipe heat exchanger. Adv. Powder Technol. 2018, 29, 273-282. [CrossRef]

26. Rehman, A.; Hussain, A.; Nadeem, S. Physical aspects of convective and radiative molecular theory of liquid originated nanofluid flow in the existence of variable properties. Phys. Scr. 2021, 96, 035219. [CrossRef]

27. Hussain, A.; Rehman, A.; Nadeem, S.; Malik, M.Y.; Issakhov, A.; Sarwar, L.; Hussain, S. A combined convection carreauyasuda nanofluid model over a convective heated surface near a stagnation point: A numerical study. Math. Probl. Eng. 2021, 2021, 6665743. [CrossRef]

28. Hussain, A.; Alshbool, M.H.; Abdussattar, A.; Rehman, A.; Ahmad, H.; Nofal, T.A.; Khan, M.R. A computational model for hybrid nanofluid flow on a rotating surface in the existence of convective condition. Case Stud. Therm. Eng. 2021, $26,101089$. [CrossRef]

29. Rehman, A.; Hussain, A.; Nadeem, S. Assisting and Opposing Stagnation Point Pseudoplastic Nano Liquid Flow towards a Flexible Riga Sheet: A Computational Approach. Math. Probl. Eng. 2021, 2021, 6610332. [CrossRef]

30. Mebarek-Oudina, F.; Redouane, F.; Rajashekhar, C. Convection Heat Transfer of MgO-Ag/Water Magneto-Hybrid Nanoliquid Flow into a Special Porous Enclosure. Alger. J. Renew. Energy Sustain. Dev. 2020, 2, 84-95.

31. Abo-Dahab, S.M.; Abdelhafez, M.A.; Mebarek-Oudina, F.; Bilal, S.M. MHD Casson nanofluid flow over nonlinearly heated porous medium in presence of extending surface effect with suction/injection. Indian J. Phys. 2021, 1-15. [CrossRef] 
32. Mebarek-Oudina, F. Convective heat transfer of Titania nanofluids of different base fluids in cylindrical annulus with discrete heat source. Heat Transf. Asian Res. 2019, 48, 135-147. [CrossRef]

33. Swain, K.; Mebarek-Oudina, F.; Abo-Dahab, S.M. Influence of MWCNT/Fe3O4 hybrid nanoparticles on an exponentially porous shrinking sheet with chemical reaction and slip boundary conditions. J. Therm. Anal. Calorim. 2021, 1-10. [CrossRef]

34. Noghrehabadi, A.; Pourrajab, R.; Ghalambaz, M. Effect of partial slip boundary condition on the flow and heat transfer of nanofluids past stretching sheet prescribed constant wall temperature. Int. J. Therm. Sci. 2012, 54, 253-261. [CrossRef]

35. Nadeem, S.; Ur Rehman, A.; Mehmood, R.; Adil Sadiq, M. Partial Slip effects on a rotating flow of two-phase nanofluid over a stretching surface. Curr. Nanosci. 2014, 10, 846-854. [CrossRef]

36. Hayat, T.; Nadeem, S.; Khan, A.U. Rotating flow of $\mathrm{Ag}-\mathrm{CuO} / \mathrm{H}_{2} \mathrm{O}$ hybrid nanofluid with radiation and partial slip boundary effects. Eur. Phys. J. E 2018, 41, 75. [CrossRef]

37. Nazar, R.; Amin, N.; Pop, I. Unsteady boundary layer flow due to a stretching surface in a rotating fluid. Mech. Res. Commun. 2004, 31, 121-128. [CrossRef] 